\title{
Carmen da Silva em Claudia: um suspiro feminista na imprensa feminina do século XX
}

\author{
Camila Pilla de Azevedo e Souza’ \\ Caroline Casali²
}

\begin{abstract}
Resumo:
As revistas femininas tematizaram o cotidiano da mulher durante o século $\mathrm{XX}$ e conduziram suas leitoras em tendências de consumo e comportamento. Este artigo analisa as colunas publicadas pela escritora e feminista Carmen da Silva, entre 1960 e 1980, na Revista Claudia, observando especialmente a tematização da maternidade nestes textos. Para isso, optou-se pela Análise de Conteúdo de cinco colunas sobre maternidade publicadas na Revista Claudia e disponíveis na obra "O melhor de Carmen da Silva" (CIVITA, 1994). Conclui-se que os textos de Carmen da Silva, em dissonância com as matérias conservadoras da Revista Claudia, denunciavam o mito da maternidade e demais padrões de feminilidade impostos pela sociedade e, por isso, foram vanguarda do feminismo brasileiro na imprensa feminina do século XX.
\end{abstract}

palavras-chave: Carmen da Silva, maternidade, Revista Claudia.

\begin{abstract}
:
Women's magazines showed to the society how was the women's daily lives during the 20th century and led their readers into trends in consumption and behavior. This article analyzes the texts published by the brazilian feminist writer Carmen da Silva in Claudia Magazine, between 1960 and 1980. We studied the thematic of maternity in this articles, by the Content Analysis of five articles about maternity published in Claudia Magazine and available in the book "The best of Carmen da Silva" (CIVITA, 1994). It is concluded that Carmen da Silva's texts, in dissonance with the conservative articles of Claudia Magazine, denounced the myth of motherhood and other standards of femininity imposed by society and, for this reason, Carmen da Silva were the vanguard of Brazilian feminism in the female press of the 20th century.
\end{abstract}

keywords: Carmen da Silva, motherhood, Claudia Magazine.

\footnotetext{
1 Jornalista pela Universidade Federal de Santa Maria, Historiadora pela Universidade Federal do Rio Grande e Funcionária Pública da Prefeitura Municipal do Rio Grande. camilapilla@gmail.com

2 Doutora em Ciências da Comunicação. Professora Adjunta do Centro de Ciências Socioorganizacionais da Universidade Federal de Pelotas. carolcasali@gmail.com
} 


\section{VOZES $_{\text {\&IÁLORO }}^{\mid}$}

Itajaí, V. 20, n.01, jan-jun 2027

\section{Introdução: conhecendo Carmen e Claudia}

Falar em revista feminina é quase uma redundância em termos, "quando se fala em revista, logo se pensa em mulher. A revista é a mídia mais feminina que existe" (MIRA, 2001, p. 43). A relação construída entre leitora e revista, durante o século XX, contribuiu na construção de comportamentos esperados para o feminino em diferentes instâncias da vida da mulher. Por isso, muitas revistas femininas conquistaram seu público e se mantém no mercado até hoje, em versões impressa ou online, como é o caso da Revista Claudia, da Editora Abril. Interessa ao presente trabalho analisar de que maneira a Revista Claudia tematizou a maternidade, entre 1963 e 1985, a partir das colunas da escritora e feminista Carmen da Silva na revista. Para isso, iniciamos com a apresentação de Claudia e de Carmen.

A Revista Claudia surge no panorama brasileiro da década de 1960, inovando em formato e conteúdo; em oposição às revistas femininas do momento, que adotavam o formato de fotonovela, ela se apresenta como um 'guia prático para todas as horas'.

O lançamento da revista Claudia pelo Grupo Abril, em outubro de 1961, é apontado, ao lado do Novo Estatuto da Mulher Casada, como um dos indicadores da modernização dos costumes em relação às representações do sexo feminino e dos papéis atribuídos às mulheres na década de 60 no Brasil (DUARTE, 2005, p. 17).

Quando da criação de Claudia, a imprensa feminina já era sucesso no mundo ocidental, o que se viu no Brasil foi a repetição de uma fórmula comprovada. Além disso, a Revista ainda contou com um cenário comercialmente favorável, dado o desenvolvimento do mercado consumidor feminino. Desde a primeira edição, Claudia tomou como público-alvo a mulher da recente classe média que se formava no país, uma espécie de 'super-mulher': mãe, dona de casa, profissional, amiga e, mais do que tudo, linda. Não fora à toa a escolha de tal alvo, uma vez que o desenvolvimento desta nova classe inseriu no mercado as consumidoras ávidas por novidades, como eletrodomésticos, acessórios mirabolantes de pouca utilidade, cosméticos e itens relacionados à moda. É para estas mulheres que a Revista é pensada, diagramada e vendida; e é com estas mulheres que se estabelece a relação de cumplicidade pretendida já na escolha do nome do periódico: 'Claudia', evocando uma amiga confidente (DUARTE, 2005).

Para sobreviver a décadas de transformação social, a própria Revista precisou renovar-se frequentemente. Mesmo tendo nascido já sob a égide do capitalismo, totalmente focada no emergente mercado feminino, Claudia acompanhou as intensas mudanças econômicas, políticas e sociais vividas pelo país na segunda metade do século XX, remodelando-se tanto na forma quanto no conteúdo. Sobre a evolução de Claudia: 


\section{VOZES $_{\text {\&IÁLORO }}^{\mid}$}

Itajaí, V. 20, n.01, jan-jun 2021

Em 1978, Claudia sente os primeiros sinais de envelhecimento. Ela que fora a revista feminina mais avançada dos anos 60 procurava rejuvenescer para enfrentar a concorrência. Nesse ano, a revista sofre uma reformulação: tem o seu formato reduzido e a introdução de novas seções. Embora procurando 'remoçar', ela continua voltada para as preocupações da mulher de classe média, dona de casa, enfim, para o lar e o consumo. Tendo decidido acompanhar sua geração em termos de moda, decoração e estilo, Claudia acabou ficando mais próxima da leitora de 30 a 40 anos. (...) A mudança mais significativa no perfil da leitora ocorre na faixa de idade: em 1979, 51\% tinha entre 20 e 40 anos, número que sobe pra 58\% em 1994 (...) Com essa receita Claudia tornou-se a revista feminina mais vendida no país e segunda entre todas as revistas (MIRA, 2001, p. 61).

A Revista Claudia se mantém no mercado competitivo do início do século XXI, mas interessa, aqui, pensar as vozes dissonantes na Revista que contribuíram na construção dos papeis esperados da mulher do século XX. A despeito de ser uma revista inovadora no formato, em temas e mesmo no apelo mercadológico, Claudia se manteve tradicional na abordagem dos conteúdos durante o século XX. Pró-virgindade e devota da ideia de esposa fiel, Claudia continuava vendendo a imagem da boa moça que a família brasileira preservara, "a moral favorável ao homem estava presente em vários momentos da Revista, até mesmo quando ela se propunha a falar contra preconceitos” (DUARTE, 2005, p. 25). Mas Claudia também abordava assuntos polêmicos e tabus, porque já existia um clima favorável para tanto, demarcado pelas dúvidas que chegavam à redação através das cartas de leitoras. E aí entra Carmen da Silva.

Claudia trazia claramente outro diferencial, em relação a publicações femininas produzidas até então: a possibilidade de vozes dissonantes dentro de uma mesma revista. A presença de articulistas proporcionava variedade de ideias e pontos de vista. Através da seção de cartas, também era possível medir a repercussão de alguns temas e polêmicas suscitados. Introduziu-se, aos poucos o debate, retirando-se essa tarefa mais a cargo das leitoras (DUARTE, 2005, p. 36).

Carmen da Silva fora uma das colunistas mais emblemáticas, sua atuação na Revista é lembrada ainda hoje como um suspiro feminista nos primórdios da imprensa feminina. Carmen nasceu em 31 de dezembro de 1919, na cidade de Rio Grande, no Rio Grande do Sul. Ainda jovem, deixou sua cidade natal rumo a então capital brasileira: Rio de janeiro. Hoje, poucos sabem que Carmen foi uma das precursoras do feminismo no Brasil, jornalista de reconhecimento nacional, autora de obras ficcionais, devota da psicanálise e carinhosamente apelidada de mulheróloga por suas leitoras (DUARTE, 2005).

Carmen da Silva resolveu enviar uma carta se apresentando à chefia da redação de Claudia, em 1963. Endereçada ao diretor da revista, Luís Carta, a correspondência manifestava o desejo de escrever sobre a condição da mulher brasileira, mostrando, para as leitoras, a necessidade 


\title{
VOZES $_{\text {\&IÁLORO }}^{\mid}$
}

Itajaí, V. 20, n.01, jan-jun 2027

de se prepararem para assumir novos papéis na sociedade (DUARTE, 2005, p. 36).

Assim começou a duradoura relação de Carmen e Claudia, como conta a pesquisadora Ana Rita Fonteles Duarte (2005) na obra de maior vulto publicada sobre a articulista "Carmen da Silva: o feminismo na imprensa brasileira". Carmen escreveu uma coluna na Revista Claudia chamada "A arte de ser mulher", por 22 anos ininterruptos. Nesse espaço, a jornalista respondia cartas enviadas por leitoras aflitas que abriam seu coração para a mulheróloga. Os temas eram tantos quanto as cartas enviadas: relacionamentos (amorosos, sexuais, afetivos, familiares, amizades etc.), profissão/carreira, maternidade (controle de natalidade, aborto, relação pais e filhos etc.), identidade, feminismo x machismo, entre outros.

Em setembro de 1963, Carmen publicou sua primeira coluna de título "A Protagonista”, papel que ela conclamava todas as mulheres do mundo a assumirem, e manteve a regularidade de publicações até seu falecimento, em abril de 1985. Em junho de 1985, dois meses após sua morte, foi publicado seu último artigo "O hábito de engolir sapo para manter marido a qualquer preço", em que critica os extremos aos quais se submetem as mulheres na esperança de "salvar o relacionamento".

Carmen criou uma relação de confiança e intimidade com suas leitoras, dirigindose diretamente a elas e chamando-as para as lutas feministas. Sua base psicanalítica davalhe instrumentos para uma análise profunda das cartas que recebia. Também por isso seus textos eram trabalhados artesanalmente, suas escolhas léxicas evidenciavam a procura da palavra perfeita e, assim, Carmen não se fazia fácil ou óbvia.

No primeiro parágrafo da primeira coluna publicada em 1963, Carmen já identificava suas interlocutoras:

\begin{abstract}
Não é necessário muita perspicácia para perceber sintomas de insatisfação nas mulheres de hoje. Casadas e solteiras, ociosas e trabalhadoras, estudantes e profissionais, artistas e donas de casa, todas elas em algum momento deixam transparecer resquícios de frustração, um desejo ora nostálgico, ora invejoso, de outra existência diferente, outro caminho distinto ao que escolheram - como se a felicidade estivesse lá (SILVA apud CIVITA, 1994, p. 17).
\end{abstract}

Além dos indícios explícitos como o trecho acima, a natureza da coluna e a forma como se abordavam os temas, a partir de problemas pontuais indicados pelas leitoras, também delineavam nitidamente um perfil da mulher com quem Carmen conversava. Por duas décadas, a mulheróloga manteve sua coluna fazendo dela uma tribuna para as causas feministas. Depois de seu falecimento, a Revista anunciou que não manteria a coluna por ser Carmen insubstituível, fato inquestionável.

Assim se constata a existência do paradoxo Carmen e Claudia, uma vez que a Revista é tida como paternalista e "Carmen da Silva é unanimidade: todos reconhecem o seu pioneirismo na divulgação dos ideais feministas” (MIRA, 2001, p. 57). 


\section{VOZES $_{\text {\&IÁLORO }}^{\mid}$}

Itajaí, V. 20, n.01, jan-jun 2021

Os nomes de Carmen e Claudia se complementam na história do feminismo brasileiro. Carmen questionou o papel da mulher no lar, no casamento, na família, na sociedade e instigou à reflexão, à mudança. No entanto, o grande filão da revista sempre esteve associado ao mundo doméstico. A proposta da revista pouco se alterou desde a sua criação (FERREIRA, 2006, p. 33).

É nesse paradoxo entre o discurso conservador da Revista e o discurso avant-garde de Carmen que se instaura a relação Carmen e Claudia, "Carmen da Silva trazia proposta nova em relação a esse tipo de discurso [tradicional], na medida em que incentivava a independência feminina” (DUARTE, 2005, p. 41). As críticas de Carmen começavam no próprio formato de 'consultório sentimental' que as seções de cartas de leitoras possuíam até então, censurando a efemeridade, a generalização e a manutenção da ideia do feminino como essência. Assim "a diferença entre o consultório tradicional e o que começou a ser trabalhado por ela, não dizia respeito ao teor dos questionamentos e desabafos feitos pelas leitoras, mas à própria forma de respondê-los” (DUARTE, 2005, p. 43).

Desde a publicação do primeiro periódico feminino que se tem registro no século XVII na Inglaterra, o Lady’s Mercury, já se constata a existência do espaço caracterizado como 'consultório sentimental'. Tal espaço consiste em seção de cartas de tom confessional onde as leitoras buscam remédio para toda sorte de males, desde um amor não correspondido até uma gravidez indesejada, além de prestar uma espécie de jornalismo de serviço onde são divulgadas informações de utilidade pública (BUITONI, 1990).

\footnotetext{
As revistas exploravam a potencialidade do consultório sentimental, seja de um modo mais sensacionalista (...) ou desenvolvendo psicologismos, como MarieClaire e Elle. O consultório sentimental nasceu com a imprensa feminina e até hoje resiste, mesmo em publicações mais pretensiosas. Assuntos e linguagem são escolhidos de acordo com o público (BUITONI, 1990, p. 65).
}

Mas a forma como Carmen atendia suas leitoras também se diferenciava do consultório tradicional, ela procurava fugir de receitas prontas e visões generalistas, atendendo individualmente cada problema, estimulando as leitoras a refletirem sobre as situações expostas.

A principal mudança dizia respeito à forma de encarar ou diagnosticar os problemas femininos. Carmen procurava reforçar a tomada de atitude individual por parte das mulheres, na mudança de suas situações. Suas intervenções, embora comprometidas com a causa feminista, evitavam, no entanto, o aconselhamento direto, ou seja, não configuravam o quadro claro de atitudes a serem adotadas pelas leitoras (DUARTE, 2007, p. 200).

Nesse sentido, mais do que acalmar as leitoras, Carmen procurava tirá-las do lugar comum, da zona de conforto, através de questionamentos psicanalíticos. Por isso, também, 


\section{VOZES $_{\text {\&IÁLORO }}^{\mid}$}

Itajaí, V. 20, n.01, jan-jun 2021

é interessante observar que, desde as primeiras colunas, o conflito discursivo entre Carmen e Claudia estava lá:

Em vários momentos, a escrita de Carmen da Silva se chocava diretamente com outros discursos presentes em Claudia, seja nas matérias jornalísticas, nos editoriais ou nos próprios anúncios publicitários veiculados. Isso nos faz pensar que sua permanência durante 22 anos, escrevendo na mesma seção, tenha demandado momentos de negociação constante de Carmen com a direção da revista e certa cautela na escolha e no tratamento das temáticas e dos termos a serem utilizados, embora saibamos que Claudia já abria espaço para o discurso mais liberalizante (DUARTE, 2005, p. 45).

Fica claro aqui que Carmen e Claudia abordavam os mesmos temas de formas distintas, por exemplo, enquanto a Revista defendia a instituição do matrimônio, a articulista incentivava a emancipação feminina. Não existem registros de Carmen denunciando censura por parte da Revista, mas após a sua morte foram encontrados bilhetes onde a articulista reclamava de modificações feitas em seu texto; a Revista, por sua vez "apesar de negar qualquer tipo de interferência no trabalho de Carmen da Silva, acabava por utilizar artifícios os mais diversos para filtrar as ideias feministas" (DUARTE, 2005, p. 48).

Enquanto Claudia surgia como uma proposta de revista feminina, Carmen se afiliava às ideias feministas: "como muitas jornalistas da imprensa feminina, Carmen se envolveu com as propostas do movimento feminista. Utilizou a seção de Claudia como a tribuna, onde desenvolveu um trabalho lento e gradual de conscientização das mulheres" (DUARTE, 2005, p. 50). Por isso, é consenso na literatura especializada a atuação de Carmen enquanto agente defensora e divulgadora dos ideais feministas.

Carmen da Silva foi uma das intelectuais feministas mais influentes no período em que atuou na revista Claudia, uma das mais conhecidas da grande imprensa feminina. Nesse contexto histórico, a presença de Carmen da Silva nas páginas de Claudia, revista de padrão para mulheres da classe média, é um fenômeno singular. Carmem praticou, em um veículo da grande imprensa feminina conservadora do Brasil, um jornalismo feminista (KOSHIYAMA, 2001, p. 03).

Nesse sentido, enquanto Claudia, no geral, corrobora com a construção do discurso sobre uma mulher submissa, as colunas de Carmen tentam subvertê-la, tratando a mulher em sua autonomia, com suas especificidades, reivindicando pelo seu direito à diferença, à unicidade, de forma que "procurava reforçar a tomada de atitude individual por parte das mulheres, na mudança de suas situações" (DUARTE, 2005, p. 44). Como parte desses discursos dissonantes, analisamos a tematização da maternidade nos textos de Carmen da Silva para a Revista Claudia. 


\section{VOZES $_{\text {\&IÁLORO }}^{\mid}$}

Itajaí, V. 20, n.01, jan-jun 2021

Para analisá-la, cumpre, primeiramente, conceitualizar maternidade. A priori, a maternidade é identificada como a condição biológica de reprodução característica das fêmeas. Nesse sentido, fica condicionada à mulher a responsabilidade de gestão da prole.

Sob bases biológicas como a concepção, gravidez, gestação, parto e amamentação, a maternidade foi considerada por diversas culturas e por longos períodos, como sendo a prova natural e cabal de que à mulher cabe a principal responsabilidade pelo cuidado de crianças dentro e fora das famílias, que é exatamente isso que desejam, que nisso está depositado seu maior prazer, e que é aí que obterão seus êxitos (STASEVSKAS, 1999, p. 6).

Confunde-se então a carga materna com os processos biológicos inerentes ao processo reprodutivo. Uma das lutas do feminismo contemporâneo, a partir da década de 1950, é a contestação do determinismo biológico que resguardava às mulheres um destino social de mães. Em oposição a esse entendimento, o movimento feminista passa a compreender a maternidade como uma construção social, o que possibilitou perceber os papéis designados pela sociedade patriarcal às mulheres.

Com base nesta evidência, a crítica feminista considerava a experiência da maternidade como um elemento-chave para explicar a dominação de um sexo sobre outro: o lugar das mulheres na reprodução biológica gestação, parto, amamentação e consequentes cuidados com as crianças - determinava a ausência das mulheres no espaço público, confinandoas ao espaço privado e à dominação masculina (SCAVONE, 2001, pp. 138-139).

Com o movimento feminista, o momento de recusa da maternidade evoluiu para uma reflexão do papel da maternidade na condição feminina, levando à sua valorização enquanto um 'poder' restrito às mulheres e indisponível aos homens. Então, o movimento feminista promoveu a desconstrução desta recusa, provando que a dominação masculina não se dá pelo acontecimento biológico da reprodução, mas sim pelas relações sociais construídas a partir da maternidade. Nesse sentido, maternidade se entende como algo bem mais amplo que o simples processo de reprodução, extrapolando conceitos como 'qualidade de mãe' ou 'característica de fêmeas que têm a capacidade de gerar um novo ser vivo'.

Para Correia (1998, p. 366), "maternidade não corresponde a um acontecimento biológico, mas a uma vivência inscrita numa dinâmica sócio-histórica. Envolve prestação de cuidados, envolvimento afectivo (...) em medidas variáveis”. Nessa perspectiva, o conceito de instinto materno também é questionado enquanto condição biológica, estando sujeito a uma série de fatores sociais, culturais e até profissionais, "o amor materno não constitui um sentimento inerente à condição de mulher, ele não é um determinismo, mas algo que se adquire” (BADINTER, 1985, p. 01). Percebe-se, então, a maternidade como construto social e que deve ser entendida no contexto sócio-histórico em que se insere. 


\section{VOZES $_{\text {\&DÁLORO }}^{\mid}$}

Itajaí, V. 20, n.01, jan-jun 2021

Carmen da Silva, entre 1963 e 1985, problematizava a maternidade como construto social e criticava os papeis atribuídos às mulheres pela sociedade patriarcal. Interessa a este texto, especialmente, analisar essa tematização da maternidade nos textos de Carmen da Silva na Revista Claudia.

\section{Metodologia: investigando Carmen em Claudia}

Para pesquisar a tematização da maternidade nas colunas da escritora e feminista Carmen da Silva, publicadas na Revista Claudia, optou-se pela Análise de Conteúdo de colunas selecionadas.

A Análise de Conteúdo é uma metodologia de pesquisa que permite organizar sistematicamente o corpus de pesquisa em categorias de estudo através de um processo de desconstrução e reconstrução do texto. Seguindo os princípios de Bardin (1979) para Análise de Conteúdo, constatou-se que, enquanto método, a análise se dá em três momentos: a pré-análise, a exploração do material e o tratamento dos resultados, inferências e interpretações.

Na etapa de pré-análise, tem-se o contato com os documentos e seleção da amostra, a leitura exaustiva e o espaço para inferências intuitivas e primeiras impressões. Por ocasião desta etapa, foi selecionado como corpus de análise cinco colunas sobre maternidade dispostas na obra "O melhor de Carmen da Silva" (CIVITA, 1994). Não foi possível identificar as datas de publicação das colunas de Carmen, uma vez que não tivemos acesso aos originais e na compilação não existe tal informação. Além dessas cinco colunas, analisamos também a edição da Revista Claudia publicada em maio de 2013 (edição de comemoração ao dia das mães), para compreender de que maneira o discurso de Carmen da Silva estava posicionado como vanguarda em comparação ao discurso da Revista Claudia no início do século XXI.

$\mathrm{Na}$ fase de exploração do material, ocorre a aplicação dos procedimentos e operações formuladas durante a pré-análise. Com o intuito de compreender de que maternidade falam Carmen e Claudia, empreendeu-se a análise temática das colunas que compõem o corpus. Segundo Bardin, "fazer uma análise temática consiste em descobrir os núcleos de sentido que compõem a comunicação e cuja presença, ou frequência de aparição podem significar alguma coisa para o objetivo analítico escolhido” (BARDIN, 1979, p. 105).

O levantamento de temas-eixos nos textos analisados - cinco colunas de Carmen da Silva e a edição de maio de 2013 da Revista Claudia - indica a presença de seis principais categorias nos textos sobre maternidade: maternidade-conceito, relação mulher-corpo, relação homem-mulher, emancipação da mulher, saúde pública e sexualidade. Essas categorias, amplamente relacionadas à maternidade na literatura, estão descritas na Tabela 1. 
Tabela 1. Categorias de análise da maternidade nas colunas de Carmen de Silva e na edição da Revista Claudia de maio de 2013.

\begin{tabular}{|c|c|}
\hline $\begin{array}{l}\text { Categorias relacionadas ao } \\
\text { tema maternidade }\end{array}$ & Descrição da categoria \\
\hline Maternidade-conceito & $\begin{array}{l}\text { abrange formas de maternidade, desde a mãe mito até a } \\
\text { mãe ausente, incluindo a não maternidade. }\end{array}$ \\
\hline Relação mulher-corpo & $\begin{array}{l}\text { aborda privações e padrões impostos à mulher e o direito } \\
\text { à autonomia corporal. }\end{array}$ \\
\hline Relação homem-mulher & $\begin{array}{l}\text { abrange o relacionamento conjugal e padrões da } \\
\text { sociedade machista. }\end{array}$ \\
\hline Emancipação da mulher & denuncia a opressão e coisificação da mulher. \\
\hline Saúde pública & $\begin{array}{l}\text { pauta problemas sociais relacionados às condições } \\
\text { femininas, como políticas de natalidade, aleitamento, } \\
\text { licença maternidade. }\end{array}$ \\
\hline Sexualidade & discute a sexualidade feminina. \\
\hline
\end{tabular}

Finalmente, a aplicação do método se encerra com o tratamento dos resultados obtidos e a interpretação, quando o pesquisador ordena os resultados a fim de inferi-los e interpretá-los (BARDIN, 1979). Os resultados apresentados a seguir analisam as categorias e o que elas revelam sobre as colunas de Carmen da Silva, em comparação ao discurso da Revista Claudia no século XXI.

\section{Resultados: analisando Carmen em Claudia}

A partir dos procedimentos da Análise de Conteúdo, foram elencadas seis categorias recorrentes nos textos de Carmen da Silva e Claudia sobre maternidade: maternidade-conceito, relação mulher-corpo, relação homem-mulher, emancipação da mulher, saúde pública e sexualidade.

Em relação ao tema-eixo maternidade-conceito, Carmen da Silva apresenta o que ela chama de "mito da maternidade", no qual a mãe é descrita como um ser sublime, idealizado, mistificado pelos homens e, então, denuncia essa sacralização como opressora à mulher. Suas colunas definem o "mito da maternidade" em trechos como: "a santa mãe dos nossos filhos, a suprema inspiração da humanidade a razão de ser da nossa vida" (SILVA apud CIVITA, 1994, p.199), "sublime, assexuada, abnegada, puro amor altruísta” (SILVA apud CIVITA, 1994, p.211) e "perfeita, maravilhosa, assexuada, altruísta, puro amor" (SILVA apud CIVITA, 1994, p. 215). Ao mesmo tempo em que Carmen denuncia a sacralização da gestação, elabora a opressão gerada nesse mito: "para a mulher, a sacralização de seu corpo é um péssimo negócio: posta num pedestal, ela passa a pertencer a quem a colocou ali” (SILVA apud CIVITA, 1994, p. 198). Em outros momentos, a feminista reflete sobre a maternidade imposta, como nas passagens: "mulher que não deseja filhos-exemplo é levada a julgar-se quase um monstro” (SILVA apud CIVITA, 1994, 


\section{VOZES $_{\text {\&IÁLORO }}^{\mid}$}

Itajaí, V. 20, n.01, jan-jun 2021

p. 196), "não quero que me enfiem culpas na cabeça por ter filhos ou não os ter" (SILVA apud CIVITA, 1994, p. 202) e "maternidade é escolha, não obrigação" (SILVA apud CIVITA, 1994, p. 202).

Enquanto Carmen da Silva, entre 1960 e 1980, buscava destituir a mulher de seu altar sagrado de mãe, buscando revelar à leitora a maternidade como escolha e sua autonomia de ser dotada de desejos e de limitações, Claudia, no início do século XXI, recupera a imagem da "mãe-mito", da "supermãe", em trechos como: "exercício da missão civilizatória que é a maternidade" (CLAUDIA, 2013, p. 22), "dedicam uma vida à casa e à família para que tudo corra bem para a gente" (CLAUDIA, 2013, p. 64), e "mãe que é mãe parece Bombril e desdobra-se em 1001 utilidades" (CLAUDIA, 2013, p. 64). Normalizase, assim, a partir de adjetivos como mulher descolada, trabalhadora, moderna, atualizada, a sobrecarga atribuída às mulheres na obrigação de administrar, com primor, a rotina da casa, a jornada de trabalho, o relacionamento amoroso e o cuidado dos filhos, para que "tudo corra bem para a gente", ou seja, para o bem do outro. Reitera-se, então, uma imagem mágica de maternidade, como se fosse um superpoder, um dom que as mulheres possuem de "dar conta do recado".

Carmen, nos textos em que aborda as categorias "relação mulher-corpo" e "relação homem-mulher", aponta a dicotomia entre a autonomia corporal feminina e a apropriação do corpo feminino pelo homem, problematizando os modelos femininos criados pela sociedade patriarcal, como se observa nas citações: "domínio da sociedade sobre o corpo e a mente da mulher" (SILVA apud CIVITA, 1994, p. 197), "o corpo da mulher continua sendo propriedade indiscutida do homem” (SILVA apud CIVITA, 1994, p. 204), e "criar na mulher uma intimidade com o próprio corpo e suas funções" (SILVA apud CIVITA, 1994, p. 199). Carmen denuncia os padrões de feminilidade impostos pela sociedade machista que "desposou a mulher até do próprio corpo" (SILVA apud CIVITA, 1994, p. 195) deixando-a sujeita "às necessidades, aos caprichos e as fantasias dos homens" (SILVA apud CIVITA, 1994, p. 195). Assim, a feminista reivindica para a mulher o direito de existir, "reconquistando a posse real de si mesma, corpo e identidade, consciência e autonomia” (SILVA apud CIVITA, 1994, p. 200). Carmen também problematiza o papel de marido e pai e faz críticas à tradicional família brasileira, baseada na mulher que assume um papel servil e submisso. De forma geral, Carmen delata o "antigo padrão de relações familiares baseadas na distância, no autoritarismo, na rigidez" (SILVA apud CIVITA, 1994, p. 213) em defesa de um "modelo inédito de família feliz e capaz de educar para a felicidade" (SILVA apud CIVITA, 1994, p. 213), considerando a corresponsabilização de todos nesse processo.

Na Revista Claudia do século XXI, também há uma abordagem que questiona temas relacionados ao machismo e papéis impostos ao homem e à mulher nas relações familiares, em trechos como: "não posso criar uma menina numa sociedade que degrada e desrespeita a individualidade da mulher” (CLAUDIA, 2013, p. 52), "nas primeiras 


\section{VOZES $_{\text {\&IÁLORO }}^{\mid}$}

Itajaí, V. 20, n.01, jan-jun 2021

semanas de vida do primeiro filho, foi o marido que a ensinou a trocar fraldas e era quem levantava e buscava o bebê no berço para as mamadas" (CLAUDIA, 2013, p. 60), e "sobre o que os homens poderiam fazer para contribuir com o avanço profissional das mulheres, respondeu: 'lavar a roupa" (CLAUDIA, 2013, p. 60). Destarte, a Revista apresenta uma postura dúbia, por vezes crítica e em outras conservadora, oscilando entre a censura à sociedade machista e a visão ultrapassada de uma supermãe responsável pelo zelo e felicidade de todos ao seu redor. Essa postura dúbia se dá sobre outras categorias, como emancipação da mulher, saúde pública e sexualidade, quando a Revista Claudia aborda a necessidade de a mãe se despir de culpas e, ao mesmo tempo, projeta a ela a necessidade de superpoderes maternos - sem os quais a mãe não conseguiria exercer outros papéis enquanto mulher.

Carmen, entre 1960 e 1980, apresenta temáticas claramente relacionadas às pautas feministas, sob as quais aborda os mecanismos de opressão e alienação da mulher e os meios de libertação feminina, como em: "toda nossa educação é voltada para preparar a mulher para o homem" (SILVA apud CIVITA, 1994, p. 207), e "receio ao esclarecimento, a tomada de consciência, com seu inevitável efeito desalienante" (SILVA apud CIVITA, 1994, p. 199). Os ideais feministas perpassam todos os textos da escritora, como um lugar de fala, extrapolando o conceito de tema do discurso. A jornalista critica a opressão feminina e o que chama de "coisificação" da mulher, pela qual a mesma é "reduzida a um objeto de manipulação social” (SILVA apud CIVITA, 1994, p. 198).

Em relação à categoria saúde pública, Carmen da Silva aborda temas como o aborto, a falta de incentivo ao aleitamento, a divulgação e finalidade das políticas de natalidade e a licença maternidade, em trechos como: "no Brasil são provocados dois milhões de abortos clandestinos por ano" (SILVA apud CIVITA, 1994, p. 205), "há toda uma estrutura médico-social voltada para alimentação artificial” (SILVA apud CIVITA, 1994, p. 209), "ao retornar ao emprego, após a licença-maternidade, a grande preocupação da mulher é provar que nada mudou pelo fato de ela ter gerado um filho" (SILVA apud CIVITA, 1994, p. 210) e "não aceito que o estado se omita no que é seu dever constitucional - prestar assistência social concreta à maternidade e à infância” (SILVA apud CIVITA, 1994, p. 202). A presença destes temas indica uma problematização ampla da condição feminina, inserindo Estado e sociedade no debate, de forma a corroborar com a ideia de um posicionamento político assumido pela autora.

Por fim, na categoria "sexualidade", destaca-se as falas da escritora que abordam a fêmea sexual e o impulso sexual como algo natural às mulheres: "a frigidez é aceita como fatalidade" (SILVA apud CIVITA, 1994, p. 197), "as tentações, os freios, o desejo" (SILVA apud CIVITA, 1994, p. 195) e "satisfação erótica” (SILVA apud CIVITA, 1994, p. 212). Para Carmen, a mulher deve reconquistar seu direito ao corpo e, consequentemente, a sua sexualidade, deixando de se privar de seus impulsos por imposições morais. Segundo a autora, "muitíssimas mulheres se angustiam ante seus impulsos sexuais" (SILVA apud 


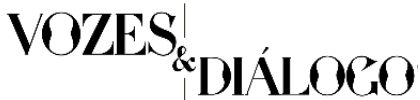

Itajaí, V. 20, n.01, jan-jun 2021

CIVITA, 1994, p. 196) quando, na verdade, a mulher precisa perceber-se como "a fêmea sexual, capaz de reivindicar e obter prazer" (SILVA apud CIVITA, 1994, p. 212).

Carmen da Silva, entre 1960 e 1980, em uma revista dentre as tantas conservadoras da época, delatava o caráter estrutural das violências sobre o corpo e a mente feminina. Enquanto as revistas buscavam normalizar e regrar os papeis que a mulher deveria assumir no privado e no público, a feminista Carmen denunciava essa condição e buscava apresentar outras possibilidades de espaços a serem ocupados pela mulher. Essa dissonância entre o discurso de Carmen e de Claudia é perceptível nos textos que tratam de maternidade, na época e hoje: enquanto a Revista Claudia, em 2013, continuava a promover a imagem sagrada da supermãe que concentra poderes e responsabilidades sobre todos e acima de si mesma, Carmen da Silva, em 1960, já era um suspiro de feminismo na mídia conservadora, denunciando opressões e buscando libertar a mulher das amarras construídas socialmente para ela.

\section{Considerações finais: por mais Carmens em Claudias}

No cruzamento entre memória, história, literatura e jornalismo, Carmen surgiu como a interseção que convergiu numa só persona. Em seus textos sobre maternidade, Carmen explorou a complexidade da mulher, problematizando seus múltiplos papéis e funções sociais. A maternidade em Carmen não se resume ao ser mãe, para ela a mulher é protagonista e seus múltiplos papéis são secundários, compondo a personagem. A mãe, a fêmea, a dona de casa, a profissional, a filha, a criança, a cidadã, enfim, todas essas mulheres coexistem em uma única mulher. Além disso, Carmen procura não falar de uma mulher abstrata e idealizada, mas sim dialogar com suas leitoras, falar a cada uma e a todas elas.

A partir das categorias que resultaram da análise de conteúdo, foram apresentadas as diversas abordagens que Carmen destina à maternidade e sua preocupação com a emancipação feminina, questionando as imposições feitas às mulheres, supostamente baseadas no determinismo biológico. Para Carmen, torna-se mãe se e quando a mulher quiser, não por dever ou por vocação biológica. Intimamente relacionado à luta feminista está o direito ao corpo e Carmen reivindica a reapropriação feminina do que sempre deveria ter sido seu: o corpo (ideia repetida em cartazes de manifestações do século XXI, em frases como "meu corpo, minhas regras").

A mãe tematizada por Carmen também tem desejos e estímulos sexuais e não deve privar-se deles, mas sim vivenciá-los de forma natural e saudável. A escritora demonstra compreender a maternidade enquanto uma construção social, exalta a maternidade livre, assumida, escolhida, e não foge de temas tabus, como ao falar de prazer sexual durante a amamentação. 


\section{VOZES $_{\text {\&IÁLORO }}^{\mid}$}

Itajaí, V. 20, n.01, jan-jun 2021

Por outro lado, ainda que oscilando entre posturas progressistas e reacionárias, a maternidade que figura hoje nas páginas de Claudia não reverbera o feminismo de Carmen da Silva. São reconhecidos os avanços feitos pela publicação, mas ponderadas as posturas conservadoras também defendidas pela mesma (DUARTE, 2005). Embora os ecos de Carmen ressoem, hoje, em passeatas, pesquisas acadêmicas, lutas feministas e na formação de coletivos pró-mulher, as revistas femininas continuam priorizando o status quo em relação aos papeis esperados de homem e mulher na sociedade patriarcal. Carmen foi, também por isso, um suspiro de feminismo na imprensa feminina do século XX.

\section{Referências bibliográficas}

BADINTER, E. Um amor conquistado: o mito do amor materno. Rio de Janeiro: Nova Fronteira, 1985.

BARDIN, L. Análise de conteúdo. São Paulo: Martins Fontes, 1979.

BUITONI, D. H. S. Imprensa feminina. São Paulo: Ática, 1990.

CIVITA, L. T. (org.). O melhor de Carmen da Silva. Rio de Janeiro: Rosa dos Tempos, 1994.

CLAUDIA, Ano LII, n 5, São Paulo, maio de 2013.

CORREIA, Maria de Jesus. Sobre a maternidade. Aná. Psicológica, Lisboa, v.16,

n.3, $\quad$ set. $1998 . \quad$ Disponível em

<http://www.scielo.gpeari.mctes.pt/scielo.php?script=sci_arttext\&pid=S0870-

$82311998000300002 \& \operatorname{lng}=$ pt\&nrm=iso $>$. Acesso em 28 jun. 2013.

DUARTE, A. R. F. Carmen da Silva - entre história e memória, uma feminista na imprensa brasileira. Fortaleza: Expressão Gráfica e Editora, 2005.

- A escrita feminista de Carmen da Silva. Caderno Espaço Feminino, v. 17, n. 01, Uberlândia, 2007.

DUARTE, K. B. Carmen da Silva: nos caminhos do autobiografismo de uma “mulheróloga”. Dissertação (Mestrado em História da Literatura) - Universidade Federal do Rio Grande, Rio Grande, 2005.

FERREIRA, M. C. As vozes negadas do feminino: uma análise discursiva em cartas de aconselhamento. Dissertação (Programa de Pós-graduação em Letras) - Instituto de Letras, Universidade do Estado do Rio de Janeiro, Rio de Janeiro, 2006. 


\section{VOZES $_{\text {\&IÁLORO }}^{\mid}$}

Itajaí, V. 20, n.01, jan-jun 2027

KOSHIYAMA, A.M. Mulheres jornalistas na imprensa brasileira. Anais do 24 . Congresso Brasileiro de Ciências da Comunicação, Campo Grande/MS, setembro 2001 [cd-rom]. São Paulo: Intercom/Portcom: Intercom, 2001.

MIRA, M. C. O leitor e a banca de Revistas: a segmentação da cultura no século XX. São Paulo: Olho d'Água/Fapesp, 2001.

SCAVONE, L. A maternidade e o feminismo: diálogo com as ciências sociais. Caderno Pagu, 2001, n.16, p.137-150.

STASEVSKAS, K. O. Ser mãe: narrativas de hoje. São Paulo, 1999. Dissertação (Mestrado) - Faculdade de Saúde Pública, USP, São Paulo, 1999. 